\title{
Comparison of use of restrictive episiotomy versus routine episiotomy in primigravidae undergoing vaginal birth at a tertiary care hospital
}

\author{
Deshwal Venus ${ }^{1}$, Rao P. S. ${ }^{2 *}$, S. Prajwal ${ }^{2}$
}

${ }^{1}$ Department of Obstetrics and Gynecology, Army Hospital RR, New Delhi, India

${ }^{2}$ Department of Obstetrics and Gynecology, Command Hospital AF, Bangalore, Karnataka, India

Received: 10 March 2017

Accepted: 01 April 2017

*Correspondence:

Dr. P. Sreenivasa Rao,

E-mail: doctorpsrao@gmail.com

Copyright: ( $)$ the author(s), publisher and licensee Medip Academy. This is an open-access article distributed under the terms of the Creative Commons Attribution Non-Commercial License, which permits unrestricted non-commercial use, distribution, and reproduction in any medium, provided the original work is properly cited.

\begin{abstract}
Background: Episiotomy is the surgical enlargement of the vaginal orifice by an incision on the perineum during the last part of the second stage of labour or delivery. Episiotomy, incision of the perineum at the time of vaginal childbirth, is a common surgical procedure experienced by women. This study is done to compare use of restrictive episiotomy and routine episiotomy in primigravidae undergoing vaginal birth.

Methods: This is a prospective cohort study designed to analyse the outcome of the restrictive use of episiotomy in comparison to routine use of episiotomy. Total 100 primigravidae women reporting to labour room in spontaneous labour/induction of labour were included and two cohorts were formed. Both the cohorts were evaluated during labour, immediate postpartum period and first postnatal day and data was tabulated and analysed.

Results: Vaginal and paraurethral tears were noted in 14\% primigravidae in the routine episiotomy group and 22.22\% in the restrictive episiotomy group with no statistically significant association. Number of cases sustaining perineal tear in restrictive group was $15.55 \%$ and extension of episiotomy in the routine group was $26 \%$ with no statistically significant association. Requirement of suturing was far less in restrictive group (20\%) as compared to routine group $(100 \%)$, as $64.45 \%$ of the patients in restrictive group delivered with an intact perineum. The restrictive use of episiotomy does not prolong the second stage of labour and has requirement of significantly less pain relief compared to the routine group. Complication rate was higher in the routine group and perineal laceration and pain severity, was less in restrictive episiotomy group. However, neonatal complications were similar in the two groups.

Conclusions: This study identified fair to good evidence suggesting that immediate outcomes following routine use of episiotomy are no better than those of restrictive use. Indeed, routine use is harmful to the degree that some proportion of women who would have had lesser injury instead had a surgical incision.
\end{abstract}

Keywords: Episiotomy, Primigravida, Vaginal delivery

\section{INTRODUCTION}

Episiotomy is a common practice for all women delivering for the first time. The reason for its popularity included substitution of a straight surgical incision, which was easier to repair, for the ragged laceration that might result in its absence. Episiotomy, incision of the perineum at the time of vaginal childbirth, is a common surgical procedure experienced by women. ${ }^{1}$ The rationale for routine prophylactic episiotomy is to protect the pelvic floor, thereby minimizing the risk of urinary incontinence and pelvic floor dysfunction.

The first mention in the literature of an incision in the perineum to facilitate difficult delivery was by a Dublin midwife, Sir Fielding Ould (1710-1789) in 1942. ${ }^{2}$ In 1799, Michaelis first recommended midline incisions in 
the perineum. In 1847, Dubois first described the mediolateral episiotomy. ${ }^{3}$

The routine episiotomy, once considered by obstetricians as a vanguard to protect the perineum, the pelvic floor, and the fetus from injuries of parturition, gradually has become less and less used in modern obstetrics. With the advent of evidenced-based medicine, obstetricians have come to realize that the risks of maternal damage outweigh the possible benefits. Rather than protecting the pelvis, it has been shown to increase postpartum perineal pain, dyspareunia, blood loss, anal sphincter laceration, rectal damage, and anal incontinence while doing nothing to reduce urinary incontinence or improve neonatal outcome. $^{4}$

Thus, came the concept that use of episiotomy should be limited to only high risk cases like short rigid perineum, shoulder dystocia, vaginal breech, face to pubis and instrumental deliveries. Restrictive episiotomy policies appear to have a number of benefits compared to routine episiotomy policies. There is less posterior perineal trauma, less suturing and fewer complications, no difference for most pain measures and severe vaginal or perineal trauma, but there was an increased risk of anterior/lateral vaginal and paraurethral trauma with restrictive episiotomy. ${ }^{5}$ Based on national hospital discharge data in United states for the year 1999, just over 35 percent of women who gave birth vaginally had an episiotomy performed; the figure was approximately 33 percent in $2000 .^{6,7}$ Figures regarding episiotomy rates in institutional deliveries in India are not available. MEDLINE search revealed only one cross sectional study by Bhatia JC et al, in 1993 wherein 23.5 per cent of institutional deliveries received an episiotomy. ${ }^{8}$

Before the twentieth century, most deliveries were performed at home by midwives, and perineal lacerations were frequently left unrepaired and less than $5 \%$ of deliveries occurred in hospitals. ${ }^{9}$ In present day obstetrics, considering the adverse effects of use of routine episiotomy in terms of perineal pain and trauma , healing complications and neonatal outcome, use of restrictive episiotomy is under trial and evaluation for better outcome and lesser complications in the form of lesser number of posterior perineal trauma, need for suturing and fewer healing complications. ${ }^{10}$

\section{METHODS}

This was a prospective cohort study conducted at a tertiary care teaching hospital. 100 primigravida women reporting to labour room in spontaneous labour/induction of labour fulfilling the following criteria- singleton pregnancy with clinically adequate pelvis, gestational age 37 to 41 completed weeks, cephalic presentation with estimated fetal weight less than $3 \mathrm{~kg}$ were included. Patients with multiple gestation, perineal length $<3 \mathrm{~cm}$ and those required instrumental deliveries were excluded from the study. Written informed consent was taken from all the patients. Final enrolment of patients was done at the time of crowning. Two cohorts were formed depending on the skill of the birth attendant to practice restrictive episiotomy. Primigravidae managed with Routine use of episiotomy formed cohort A and cohort B comprised of women subjected to Restrictive use of episiotomy. Progress of labor and delivery monitored. Both the cohorts were evaluated during labor, immediate postpartum period and first postnatal day. Under the policy of Routine or liberal use of episiotomy all primigravidae in cohort A were given an episiotomy. However, with the use of Restrictive episiotomy great restraint was observed in giving an episiotomy. Since the aim of the study was not to cause any harm to maternal and fetal health, episiotomy was given in cohort B in the following conditions- Unduly prolonged second stage of labour $\geq 2 \mathrm{hrs}$ with an unyielding perineum, need of an episiotomy to prevent more serious perineal tears, maternal exhaustion/poor maternal bearing down effort and non-reassuring fetal heart rate patterns.

Following parameters were evaluated- occurrence of vaginal/perineal, tears/extension of episiotomies, requirement of suturing and analgesia, wound complications, neonatal outcome APGAR score at $1 \mathrm{~min}$ and 5 min and NICU admission.

The patients were discharged 24 hours after delivery or more depending upon the condition of the mother and neonate. Thereafter, followed up at routine postnatal visit after six weeks and in case of any complication two weeks after discharge from the hospital. Data was tabulated and analysed. Statistical analysis was carried out by using editable and SPSS version 17. Associated $\mathrm{p}$ values were calculated assuming significance at the $\mathrm{p}$ value $<0.05$.

\section{RESULTS}

In this study, total number of deliveries analysed was 100. In cohort-A routine episiotomy was given to 50 cases and in cohort B restrictive episiotomy was practiced in 45 cases with 05 cases converted to episiotomy due to non-reassuring fetal heart pattern and prolonged second stage of labour. As these $10 \%$ of the patients who were given routine episiotomy were not enrolled in cohort $\mathrm{A}$ at the beginning of the study, so these were excluded from both the cohorts.

\section{Total subjects in both the cohorts}

- Cohort A - 50

- Cohort B - 45

According to Table 1, comparison between two cohorts based on parameters of age of mother, birth weight and gestaional age of newborn is as depicted. The difference between the mean age, birth weight and gestational age of the two groups was assessed using " $Z$ " test and it was found that there was no statistically significant difference 
between the two groups. According to Table 2, perineal length was compared between the cohort A (routine episiotomy) and cohort B (restrictive episiotomy). The difference between the mean perineal length of the two groups was assessed using Students ' $t$ ' test and it was found that there was no statistically significant difference between the mean perineal length of two groups.

Table 1: Comparison of maternal age, birth weight and gestational age.

\begin{tabular}{|c|c|c|c|c|c|}
\hline Parameter & Delivery & $\mathbf{N}$ & Mean & Std. Deviation & p value \\
\hline \multirow{2}{*}{ Age } & Routine & 50 & 23.34 & 2.96 & 0.805 \\
\hline & Restrictive & 45 & 23.2 & 2.555 & \\
\hline \multirow{2}{*}{ Birth weight } & Routine & 50 & 2.76 & 0.319 & 0.316 \\
\hline & Restrictive & 45 & 2.69 & 0.294 & \\
\hline \multirow{2}{*}{ POG } & Routine & 50 & 38.4 & 1.195 & 0.583 \\
\hline & Restrictive & 45 & 38.53 & 1.16 & \\
\hline
\end{tabular}

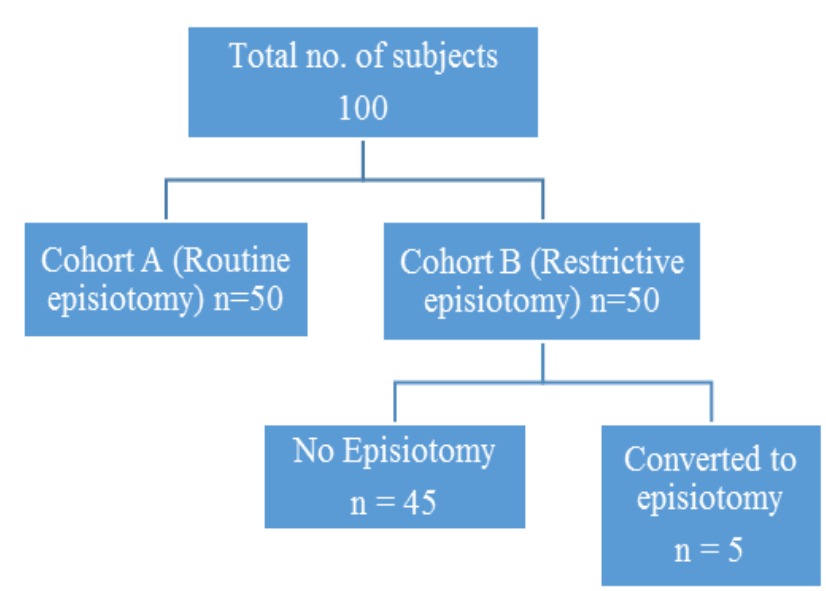

Figure 1: Distribution of patients into two cohorts.

Table 2: Comparison of perineal length between cohort $\mathrm{A}$ and cohort $\mathrm{B}$.

\begin{tabular}{|llll|l|}
\hline $\begin{array}{l}\text { Type of } \\
\text { delivery }\end{array}$ & $\mathbf{N}$ & $\begin{array}{l}\text { Mean length } \\
(\mathrm{cm})\end{array}$ & $\begin{array}{l}\text { Std. } \\
\text { deviation }\end{array}$ & $\begin{array}{l}\text { P } \\
\text { value }\end{array}$ \\
\hline Routine & 50 & 3.400 & 0.1161 & 0.255 \\
\hline Restrictive & 45 & 3.489 & 0.5055 & \\
\hline
\end{tabular}

Table 3: Comparison of second stage of labour in both the cohorts.

\begin{tabular}{|c|c|c|c|c|}
\hline Delivery & $\mathbf{N}$ & $\begin{array}{l}\text { Mean duration } \\
2^{\text {nd }} \text { stage of } \\
\text { labour (mins) }\end{array}$ & $\begin{array}{l}\text { Std. } \\
\text { deviation }\end{array}$ & $\begin{array}{l}P \\
\text { value }\end{array}$ \\
\hline Routine & 50 & 64.9 & 13.789 & 0.066 \\
\hline Restrictive & 45 & 70.07 & 13.238 & \\
\hline
\end{tabular}

According to Table 3 the mean duration of second stage of labour in the cohort A (routine episiotomy) was 64.90 min and in the cohort B (restrictive episiotomy) it was $70.07 \mathrm{~min}$. The difference between the second stages of labour for the two groups was assessed using " $Z$ " test and it was found that there was no statistically significant difference between the duration of second stage of labour in both the cohorts. Thus, depicting that the restrictive use of episiotomy does not prolong the second stage of labour.

Table 4: Comparison of intrapartum parameters in cohort $A$ and cohort $B$.

\begin{tabular}{|llll|}
\hline Parameter & $\begin{array}{l}\text { Routine } \\
\text { episiotomy }\end{array}$ & $\begin{array}{l}\text { Restrictive } \\
\text { episiotomy }\end{array}$ & $\begin{array}{l}\text { P } \\
\text { Value }\end{array}$ \\
\hline $\begin{array}{l}\text { Anterior and } \\
\text { lateral vaginal } \\
\text { and paraurethral } \\
\text { tear }\end{array}$ & $07(14 \%)$ & $10(22.2 \%)$ & 0.29 \\
\hline $\begin{array}{l}\text { Perineal } \\
\text { tear/extension } \\
\text { of episiotomy }\end{array}$ & $13(26 \%)$ & $07(15.5 \%)$ & 0.20 \\
\hline \begin{tabular}{l} 
Suturing \\
\hline
\end{tabular} & $50(100 \%)$ & $09(20 \%)$ & NA \\
\hline
\end{tabular}

According to Table 4, comparison of the two groups in terms of anterior /lateral vaginal and paraurethral tear showed that $14 \%$ (n-07) primigravida in the cohort A and $22.22 \%(n-10)$ in the cohort B sustained the tears. The type of delivery was assessed by using Chi-square test and it was found that there was no statistically significant association between vaginal/paraurethral tear and type of delivery. It was observed that the number of cases in the routine group who had extension of episiotomy was n-13 (26\%), extension of episiotomy was observed in the form of extension of apex, extension into muscle or mucosa. It was seen that the extension of episiotomy wounds was limited up to muscle and there were no third or fourth degree tears observed. In the restrictive group, perineal tear was observed in $07(15.55 \%)$ patients. The tears in the restrictive group were first and second degree perineal tears. The type of delivery was assessed by using Chisquare test and it was found that there was no statistically significant association between perineal tear and type of delivery. In cohort A n- 50 subjects $(100 \%)$ had to be sutured as episiotomy was given to all cases. Out of the 07 anterior/lateral vaginal and paraurethral tears, 04 were sutured in view of active bleed from the site. In cohort B, n-9 subjects $(20 \%)$ required suturing out of which 07 
were perineal tears and 02 were vaginal/ paraurethral tears It was noted that there was a significant reduction in requirement of suturing in cohort $\mathrm{B}$, as suturing was done only in cases which had a perineal tear or vaginal/paraurethral tear which were bleeding.

According to Table 5, it was found that the requirement of analgesia in the immediate postpartum period (within first 24 hours), restrictive group n-10 (22.22\%) required analgesics and in routine group $\mathrm{n}-25$ (50\%) of the patients required pain relief in the postnatal period. In the restrictive group, analgesia in the form of oral and per rectal medication was required for 09 patients in whom suturing was done to repair the perineal and vaginal tears and in 01 patient analgesia was required for perineal pain.

Table 5: Comparison between requirement of analgesia and healing between cohort $\mathrm{A}$ and $\mathrm{B}$.

\begin{tabular}{|c|c|c|c|}
\hline Parameter & $\begin{array}{l}\text { Routine } \\
\text { episiotomy }\end{array}$ & $\begin{array}{l}\text { Restrictive } \\
\text { episiotomy }\end{array}$ & $\begin{array}{l}\text { p } \\
\text { Value }\end{array}$ \\
\hline $\begin{array}{l}\text { Requirement of } \\
\text { analgesia }\end{array}$ & $25(50 \%)$ & $10(22.22 \%)$ & 0.005 \\
\hline $\begin{array}{l}\text { Healing } \\
\text { complications }\end{array}$ & $03(6 \%)$ & $01(2.22 \%)$ & 0.68 \\
\hline
\end{tabular}

The association between requirement of analgesia and type of delivery was assessed by using Chi-square test and it was found that there was a statistically significant association between the requirement of analgesia and type of delivery. This analysis showed that restrictive use of episiotomy had less postnatal perineal pain due to suturing of episiotomy/tears. Complication rate was higher in the form of wound inflammation, gaping and hematoma in the routine group. In the routine group total $03(6 \%)$ patients had complications, 02 in the form of wound inflammation and 01 had hematoma formation. The association between healing complication and type of delivery was assessed by using Fisher exact test and it was found that there was no statistically significant association between healing complication and type of delivery.

Table 6: Comparison of APGAR scores.

\begin{tabular}{|c|c|c|c|c|}
\hline & \multicolumn{3}{|c|}{ Delivery } & \multirow{2}{*}{ Total } \\
\hline & & Routine & Restrictive & \\
\hline \multirow{2}{*}{$1 \mathrm{~min}$} & $\begin{array}{l}\text { 4-6 (mild } \\
\text { depression) }\end{array}$ & 3 & 4 & 7 \\
\hline & $\begin{array}{l}\geq 7 \text { (no } \\
\text { depression) }\end{array}$ & 47 & 41 & 88 \\
\hline Total & & 50 & 45 & 95 \\
\hline \multirow{2}{*}{$5 \mathrm{~min}$} & $\begin{array}{l}\text { 4-6 (mild } \\
\text { depression) }\end{array}$ & 1 & 2 & 3 \\
\hline & $\begin{array}{l}\geq 7 \text { (no } \\
\text { depression) }\end{array}$ & 49 & 43 & 92 \\
\hline Total & & 50 & 45 & 95 \\
\hline
\end{tabular}

According to Table 6, APGAR scores at $1 \mathrm{~min}$ and $5 \mathrm{~min}$ interval are as given in Table 5. The association between
$1 \min (\mathrm{p}=0.70425)$ and $5 \min (\mathrm{p}=0.60174)$ APGAR score and delivery types was assessed by Fisher exact test and it was found that there was no statistically significant association between APGAR score and delivery types.

According to Table 7 , there was no difference in the neonatal outcome in the two groups. Among the study population there were 07 admissions to NICU, 03 in the cohort A and 04 in the cohort B showing no variation. The NICU admissions were attributed to low birth weight, low APGAR scores, meconium stained liquor. The association between the NICU admission and the 2 methods of deliveries was assessed using Fisher exact test and it was found that there was no statistically significant difference between the NICU admission and the 2 methods of delivery. Hence, routine use of episiotomy was not associated with a reduction in adverse neonatal outcome. The hospital stay of more than 24 hours as per the institutional policy of hospital under study was found in 10 cases due to neonatal admissions to NICU and maternal healing complications with 05 cases who stayed in the hospital for more than 24 hours in each of the cohort. In the restrictive group 04 cases had a hospital stay of more than 24 hours due to NICU admission and 01 case was readmitted after discharge for wound gaping. In the routine episiotomy group, there were 05 cases with hospital stay of more than 24hours, NICU admission led to extended stay in 03 cases and maternal healing complications (hematoma formation-01, wound inflammation-02), with one case admitted over 24hours because of coexisting neonatal and maternal healing complication.

Table 7: Neonatal outcome and hospital stay.

\begin{tabular}{|c|c|c|c|}
\hline Parameter & $\begin{array}{l}\text { Routine } \\
\text { episiotomy }\end{array}$ & $\begin{array}{l}\text { Restrictive } \\
\text { episiotomy }\end{array}$ & $\begin{array}{l}\mathbf{P} \\
\text { Value }\end{array}$ \\
\hline NICU admission & $03(6 \%)$ & $04(8.88 \%)$ & 0.88 \\
\hline Hospital stay & $\mathrm{N}=50$ & $\mathrm{~N}=45$ & \\
\hline$<24 \mathrm{hrs}$ & 45 & 40 & 0.874 \\
\hline$>24 \mathrm{hrs}$ & 05 & 05 & \\
\hline
\end{tabular}

The association between the hospital stay and the 2 methods of delivery was assessed using Yates corrected Chi-square test and it was found that there was no statistically significant difference between the hospital stay and the 2 methods of delivery.

\section{DISCUSSION}

The current study was performed to compare complications following routine and restrictive episiotomy among primigavida patients. Among the 100 cases selected 50 cases in the routine episiotomy and 45 cases in restrictive episiotomy were analysed with $10 \%$ cases $(n=5)$ in the restrictive group converted to episiotomy due to non-reassuring fetal heart pattern and prolonged second stage of labour. This finding shows that the rate of conversion to episiotomy in the restrictive group was minimal. In addition, the rate of maternal 
complications, such as perineal laceration and significant perineal pain, was less in restrictive. The results of this study indicated primigavida patients to have increased chance of retaining an intact perineum if episiotomy is carried out only when considered to be inescapable. The findings were in accordance with a few studies that have compared restrictive and routine episiotomy. ${ }^{11}$

The difference between the mean age, birth weight and gestational age and second stage of labour had no statistically significant difference between the two groups. As per Saxena et al there was no correlation of episiotomy or tears to the maternal age in both the groups. ${ }^{12}$

In the study under reference the difference between the mean perineal length of the two groups was assessed and it was found that there was no statistically significant difference between the mean perineal length of two groups. Study by Carroli $G$ et al conducted on 429 women concluded that perineal length was not associated with the risk of perineal tear. ${ }^{13}$

The mean duration of second stage of labour in the cohort A (routine episiotomy) was $64.90 \mathrm{~min}$ and in the cohort $\mathrm{B}$ (restrictive episiotomy) it was $70.07 \mathrm{~min}$. There was no statistically significant difference between the duration of second stage of labour in two groups. In a study by Clemons et al routine and restrictive use of episiotomy was found to have no significant effect on duration of second stage of labour. ${ }^{14}$

In the current study comparison of the two groups in terms of vaginal and paraurethral tear showed that $14 \%$ (n-07) primigravida in the routine and $22.22 \%$ (n-10) in the restrictive group sustained the tears. Eltorkey et al concluded in their analysis that anterior lacerations, including anterior labial lacerations, were more common in the restrictive use group. Anterior lacerations did not contribute to overall higher use of suturing, suggesting that these tears were less severe than posterior tears. ${ }^{15}$ Azar et al in 2011 conducted a study and concluded that anterior vaginal trauma was commoner in the restrictive group. ${ }^{11}$

In the present study under reference it was observed that the number of cases sustaining extension of episiotomy in the routine group was $n-13(26 \%)$ and in the restrictive group n-07 $(15.55 \%)$ of the patients had a perineal tear. In a study conducted in Indian settings by Saxena et al showed statistically significant reduction in the number of perineal lacerations in primipara and multipara with the practice of restrictive episiotomy. Thus, it would be fair to conclude that the policy of restricted use of episiotomy has a strong protective effect on the occurrence of perineal lacerations and it significantly contributed to lessen the maternal morbidity. ${ }^{12}$ In a study by Clemons et al, the total number of parturients who had perineal lacerations, in the study group was $36 \%$, which was significantly less when compared to $69 \%$ in the control group. The anal sphincter laceration rate decreased $44 \%$ with the use of mediolateral episiotomy. ${ }^{14}$ In a study by Carolli $\mathrm{G}$ et al, restrictive episiotomy resulted in less severe perineal trauma. Use of midline episiotomy in the routine group led to more severe perineal trauma. ${ }^{13}$

In the current study rate of episiotomy had reduced remarkably with $10 \%$ women delivering with an episiotomy in the restrictive group compared to routine episiotomy where $100 \%$ episiotomy rates were observed. According to the results of Argentine Episiotomy Trial Collaborative Group, the routine episiotomy should be abandoned and that episiotomy rates above $30 \%$ were not recommended. ${ }^{16}$ In a study carried out by Carroli et al on (5541 women) it was seen that in the routine episiotomy group, $75.15 \%$ of women had episiotomies, while the rate in the restrictive episiotomy group was $28.40 \% .^{13}$

In the current study $64.45 \%$ of the patients in the restrictive group delivered with an intact perineum. Adoni A et al in a study found that outcomes in the group for whom episiotomy was restricted, $21 \%$ had an intact perineum, and these women had the best outcomes with respect to pain and postpartum healing. ${ }^{17}$ As per Saxena et al the policy of restricted use of episiotomy led to $64 \%$ women delivering with intact perineum, that is, without perineal trauma due to episiotomy or tear. Restricted use of episiotomy led to significant reduction in the incidence of perineal lacerations. ${ }^{12}$

As per current study in routine episiotomy n- 50 subjects $(100 \%)$ had to be sutured as episiotomy was given to all cases and 04 of the total 07 , vaginal/ paraurethral tears in the routine group were sutured in view of active bleed from the site. In restrictive group n-9 (20\%) required suturing out of which 07 were perineal tears and 02 were vaginal / paraurethral tears. In a study by Carroli $\mathrm{G}$ et al, restrictive episiotomy resulted in less suturing compared with routine use of episiotomy. ${ }^{13}$

On comparison of the requirement of analgesia in restrictive group, $10(22.22 \%)$ of cases required analgesics and in routine group 25 (50\%) patients required pain relief in the form of oral and per rectal analgesics due to repair of tears and extension of episiotomy wounds in the immediate postpartum period. This analysis showed that practicing restrictive use of episiotomy had less postnatal perineal pain and statistically significant reduction in requirement of analgesia. Carroli et al conclude that compared with routine vs restrictive use of episiotomy resulted in use of less severe pain measures because of less severe perineal trauma and less requirement of suturing. ${ }^{13}$ As per Argentine Episiotomy Trial Collaborative Group, perineal pain was less frequent in the restrictive group. ${ }^{16}$

In this study complication rate was higher in the form of wound inflammation, gaping and hematoma in the routine group $\mathrm{n}-03(6 \%)$ and $\mathrm{n}-01 \quad(2.22 \%)$ in the 
restrictive group. The association between healing complication and type of delivery was assessed and it was found that there was no statistically significant association between healing complication and type of delivery. The Argentine trial reported no difference healing complications (hematoma, infection, or dehiscence) in both the groups. ${ }^{16}$ Carroli et al conclude that compared with routine use, restrictive episiotomy resulted in less healing complications. ${ }^{13}$

There was no difference in the neonatal outcome in the two groups in our study Among the restrictive group there were $04(8.88 \%)$ admissions to NICU and $03(6 \%)$ in the routine group thus showing no variation. In a study conducted by Saxena et al also there was no difference in the neonatal outcome in the two groups. Among this study population there were 06 admissions to NICU for birth asphyxia, 03 each in control and study group. All these neonates had been delivered with the help of an episiotomy. ${ }^{12}$

Murphy et al. performed a multi-center pilot randomized controlled trial in Ireland to investigate neonatal trauma in routine versus restrictive use of episiotomy. This is in agreement to our results and did not indicate any significant difference in both primary and secondary outcomes between two mentioned methods. ${ }^{10}$

Our study was different from the similar study which was conducted by Malik et al at Haryana in which they studied outcomes in both primigravida and multigravida separately, were evaluated perineal injuries with respect to birth weight. Our study evaluated only primigravida women. ${ }^{18}$ Apart from perineal injuries, effect on prolongation of second stage, requirement of analgesia, healing complications and neonatal outcomes were evaluated in our study.

\section{CONCLUSION}

This study identified fair to good evidence suggesting that immediate outcomes following routine use of episiotomy are no better than those of restrictive use. Indeed, routine use is harmful to the degree that some proportion of women who would have had lesser injury instead had a surgical incision. Due to low maternal complications of restrictive episiotomy, avoiding routine episiotomy in unnecessary conditions increases the rate of intact perineal and minor perineal trauma and reduces postpartum delivery pain with no adverse effects neither on maternal nor neonatal morbidities. It is necessary to establish some documented protocols to decide in which cases, when and how to perform episiotomy.

The time has come to take on the professional responsibility of setting and achieving goals for reducing episiotomy use. It is suggested that obstetricians develop guideline for performing episiotomies. The goals for quality of care must remain focused on both optimizing safety for the infant and minimizing harm to the mother.
Funding: No funding sources Conflict of interest: None declared

Ethical approval: The study was approved by the Institutional Ethics Committee

\section{REFERENCES}

1. Weber AM, Meyn L. Episiotomy use in the United States, 1979-1997. Obstet Gynecol. 2002;100(6):1177-82.

2. Ould F. A treatise of midwifery. London: J Buckland. 1741:145-6.

3. Thacker SB, Banta HD. Benefits and risks of episiotomy: An interpretive review of the English language literature, 1860-1980. Obstet Gynecol Surv. 1983;38(6):322-38.

4. Langer B, Minetti A. Immediate and long term complications of episiotomy. Am J Obstet Gynecol Obstet Biol Reprod (Paris). 2006;35(1):32-9.

5. Hartmann K, Viswanathan M. Outcomes of routine episiotomy: A systematic review, JAMA. 2005;293(17):2141-8.

6. Popovic JR. National Hospital Discharge Survey: Annual summary with detailed diagnosis and procedure data. Vital Health Stat 13. 2001;151:1206.

7. Martin JA, Hamilton BE, Ventura SJ. Births: Final data for 2000. Natl Vital Stat Rep. 2002;50(5):1-101.

8. Bhatia JC and Cleland J. Determinants of maternal care in a region of South India, Health Transition Review. 1995:127-42.

9. Nugent F. The primiparous perineum after forceps delivery. Am J Obstet Gynecol. 1935;30:249.

10. Murphy D, Macleod M, Bahl R, Goyder K, Howarth L, Strachan B. A randomised controlled trial of routine versus restrictive use of episiotomy at operative vaginal delivery: A multicentre pilot study. BJOG. 2008;115(13):1695-702.

11. Shahraki AD, Aram S, Pourkabirian S, Khodaee S, Choupannejad S. A comparison between early maternal and neonatal complications of restrictive episiotomy and routine episiotomy in primiparous vaginal delivery. J Res Med Sci. 2011;16(12):15839.

12. Saxena RK, Sandhu GS, Babu KM, Bando H, Sharma GV. Restricted use of episiotomy; J Obstet Gynecol India. 2010;60(5):408-12.

13. Carroli G, Mignini L. Episiotomy for vaginal birth. Cochrane Database Syst Rev. 2009;(1):81.

14. Clemons JL, Towers GD. Decreased anal sphincter lacerations associated with restrictive episiotomy use. Am J Obstet Gynecol. 2005;192(5):1620-5.

15. Eltorkey MM, Nuaim MA. Episiotomy, elective or selective: A report of a random allocation trial. J Obstet Gynaecol. 1994;14(5):317-20.

16. Argentine Episiotomy Trial Collaborative Group. Routine vs selective episiotomy: a randomised controlled trial. 1993;342(8886-8887):1517-18.

17. Adoni A, Anteby E. Episiotomy practice: changes and evidence-based medicine in action: the building 
controversy: episiotomy and severe perineal lacerations. Br J Obstet Gynaecol. 1991;98(5):476-8.

18. Malik J, Das S, Das A, Rai P. Judicial use of episiotomy in singleton normal vaginal deliveries at term: the changing trend. IJRCOG. 2016;5(3):882-5.
Cite this article as: Venus D, Rao PS, Prajwal S. Comparison of use of restrictive episiotomy vs routine episiotomy in primigravidae undergoing vaginal birth at a tertiary care hospital. Int J Reprod Contracept Obstet Gynecol 2017;6:1770-6. 